\title{
Use of Prophylactic Phenobarbitone for Prevention of Morbidity and Mortality in Term Neonates Following Perinatal Asphyxia
}

\author{
TAHSINUL AMIN ${ }^{1}$, ASIM KUMAR SHAHA $^{2}$, AYESHA NAJMANUR ${ }^{3}$
}

\begin{abstract}
Background: Seizures are common following perinatal asphyxia and may exacerbate secondary neuronal injury. Barbiturate therapy has been used for infants with perinatal asphyxia in order to prevent seizures. However, barbiturate therapy may adversely affect neurodevelopment leading to concern regarding its aggressive use in neonates. The objective of the study was to determine the effect of administering prophylactic barbiturate therapy on seizure control and mortality in term neonates following perinatal asphyxia.
\end{abstract}

Methodology: This was a randomized controlled trial (RCT) of prophylactic phenobarbitone therapy in term asphyxiated neonates without clinical evidence of seizures when compared to controls conducted in the neonatal ward of Sher-e-Bangla Medical College Barisal from $1^{\text {st }}$ January 2016 to $30^{\text {th }}$ June 2016.

Results: Among the 100 neonates equally divided into two groups, there was no significant difference found in clinical outcome e.g. seizures ( $8 \%$ vs. $12 \%, p>0.05)$, neurological abnormality at discharge $(10 \%$ vs. $14 \%, p>0.05)$, mortality $(12 \%$ vs. $14 \%, p>0.05)$ and major neurological disability (14\% vs. $18 \%, p>0.05)$.

Conclusion: In this study, prophylactic phenobarbitone therapy did not significantly prevent seizures in asphyxiated neonates.

Keywords: Phenobarbitone, morbidity, mortality, perinatal asphyxia.

\section{Introduction}

Perinatal asphyxia resulting in hypoxic-ischemic encephalopathy (HIE) remains an important cause of mortality and severe long-term neurologic and developmental disability in children. ${ }^{1}$ Seizures are common following perinatal asphyxia occurring in up to $60 \%$ neonates with stage II and stage III HIE and may exacerbate secondary neuronal injury. ${ }^{2}$ Barbiturate therapy has been used for infants with perinatal asphyxia in order to prevent seizures. ${ }^{2}$ However, barbiturate therapy may adversely affect neurodevelopment leading to concern regarding its aggressive use in neonates. ${ }^{3}$ Paramount in the

1. Associate Professor, Department of Neonatology, Sher-eBangla Medical College Barisal.

2. Professor \& Head, Department of Neonatology, Sher-e-Bangla Medical College Barisal.

3. Consultant of Obstetrician \& Gynaecologists, Ex. Resident, BSMMU, Dhaka

Correspondence: Dr. Tahsinul Amin, Associate Professor, Department of Neonatology, Sher-e-Bangla Medical College Barisal. Mob.: 01715734232, E-mail: tahsinul_amin@yahoo.com Received: 05 August $2017 \quad$ Accepted: 14 November 2017 treatment of HIE is the early identification of infants whose encephalopathy may be subject to treatment. ${ }^{4}$ The management of these infants has traditionally been supportive, with the goal of restoring and maintaining cerebral perfusion, maintaining glucose homeostasis, treating other organ dysfunction and treating seizures when present. ${ }^{5}$ These seizures may worsen brain injury caused by birth asphyxia. In theory, treatment with barbiturates soon after birth asphyxia may improve outcomes by preventing seizures and protecting the brain. Such treatment is called prophylaxis because it is given to prevent seizures rather than treat them once they have happened. ${ }^{6}$ Barbiturate therapy has some side effects and there are concerns that barbiturates might impair brain development. ${ }^{7}$

When present, seizures substantially increase cerebral metabolic demand, causing the release of excitatory neurotransmitters such as glutamate, lead to fluctuations in systemic arterial pressure, and result in hypoxia and hypercapnia. ${ }^{8}$ Though the degree to which seizures are associated with an increased risk 
of death and neurodevelopmental disability in this population is unclear, seizures are thought to contribute to ongoing neuronal injury following asphyxia. ${ }^{9}$ The potential benefits of preventing further neuronal injury through the treatment and prevention of seizures following asphyxia has prompted the widespread use of anticonvulsants in this population. Barbiturates, specifically phenobarbital, remain the preferred drugs of choice for the management of neonatal seizures, including seizures that occur following perinatal asphyxia. ${ }^{10}$

Phenobarbital works by reducing the cerebral blood flow with less edema, lowering the cerebral metabolic rate and lipid peroxidation in plasma and cerebrospinal fluid, scavenging free radicals, and depressing glutamate response within the brain. ${ }^{11}$ Phenobarbital can have a positive influence on the outcome of newborns with perinatal asphyxia. ${ }^{12}$ In addition to the potential anticonvulsant effects, barbiturates are also known to decrease central nervous system (CNS) metabolic rate when given in high doses, reduce calcium entry post ischemia, and scavenge free radicals. Thus, barbiturates may theoretically attenuate the cascade of damaging processes initiated by the hypoxic-ischemic insult and reduce secondary neuronal injury. ${ }^{11}$ For these reasons, many clinicians have used barbiturates, specifically phenobarbital, prophylactically with or without therapeutic hypothermia, in cases of HIE.

The therapeutic window that exists to minimize secondary injury and improve overall outcome is short (thought to be less than six hours). Following a reversible hypoxic-ischemic insult, neuronal cell death occurs in two phases. Phase one, the initial anoxic event, results in primary neuronal injury and cell death due to cellular hypoxia with exhaustion of cellular energy stores. Phase two, the reperfusion phase, occurs following a latent period and results in delayed neuronal injury during the recovery period following initial resuscitation. ${ }^{13}$ Mechanisms thought to be important in the second phase of neuronal injury include production of oxygen free radicals, intracellular calcium influx, increase in excitatory neurotransmitters, cerebral edema, and active cell death or apoptosis. ${ }^{14}$ Clinically, this second phase of injury is associated with encephalopathy and increased seizure activity. ${ }^{15}$ It is the severity of this second phase that correlates with mortality and adverse neurodevelopmental outcomes at one and four years of age ${ }^{16}$ Therapeutic cooling of the head reduces the long term adverse effects of HIE but many infants still die or suffer from neurologic impairment despite head cooling.Phenobarbital and erythropoietin are two additional therapeutic interventions in addition to head cooling in perinatal asphyxia. ${ }^{17}$ Phenobarbital acts by suppressing the oxidative cerebral metabolism and diminishing neuronal response to glutamate. High dose i.v. phenobarbital, used early after neurologic insult, lowers cerebral metabolic rate and reduces neuronal damage thereby prevents morbidity and mortality in perinatal asphyxia. ${ }^{18}$

\section{Methodology}

The study was a randomized controlled trial (RCT) conducted from January 01, 2016 to June 30, 2016 i.e. duration of the study was 6 months. The inclusion criteria were full-term infants with a gestational age e" 37 weeks, an Apgar score d" 5 at 10 minutes after birth or the need for resuscitation within 60 minutes after birth, and moderate to severe encephalopathy (lethargy, stupor, or coma, hypotonia and abnormal reflexes) but without clinical seizures within three days of age with perinatal asphyxia. Seizures were considered present if suspected clinically. Exclusion criteria were congenital anomalies, chromosomal abnormalities, congenital infections, intrauterine growth retardation and infants of diabetic mother. Types of interventions: Phenobarbitone administered as 20 $\mathrm{mg} / \mathrm{kg}$ intravenously slowly over 20 minutes, in the early neonatal period (within the first three days of life) prophylactically with the intention of preventing seizures and mortality following perinatal asphyxia.Types of outcome measures:major neurodevelopmental disability: seizures during initial neonatal period and death. The study was a randomized controlled trial (RCT) in which one group (case) given prophylactic phenobarbital before occurrence of seizures compared to another group (control) given standard treatment in perinatal asphyxia. Total 100 neonates with perinatal asphyxia were included in the study after informed consent; fifty neonates were in the case group and another 50 neonates were in the control group. Data were collected and results were analyzed by SPSS software version 12. Continuous variables were expressed as mean $\pm \mathrm{SD}$, tested by student $t$ test and Mann-Whitney test and categorical variables were expressed as number and frequency, tested by Chi-square test. Result was considered statistically significant if $p$ value is $<0.05$. The study neonates were followed up 
periodically at three months interval up to one year of age for evaluation of major neurological disabilities e.g. cerebral palsy, epilepsy.

\section{Results}

This study was a randomized controlled trial (RCT) conducted in the Neonatal ward in the Sher-e-Bangla Medical College, Barisal from January 01, 2016 to June 30, 2016.Both the case and control groups were comparable regarding birth weight, gestational age, sex ratio, mode of delivery and Apgar score at 10 minutes of life as shown in table I.
Clinical outcome such as seizures, neurological abnormalities and disabilities and mortality were not significantly higher in the case group than the control group, i.e. p value $>0.05$ as shown in table-II.

Prediction of various clinical outcome in perinatal asphyxia e.g. seizures, neurological abnormalities (poor sucking, hypotonia, poor primitive reflexes), mortality and major neurological disability (cerebral palsy, epilepsy) was shown in Table-III.

Table-I

Baseline characteristics of the neonates of both the study groups.

\begin{tabular}{lccc}
\hline Variables & $\begin{array}{c}\text { Case group } \\
(\mathrm{n}=50)\end{array}$ & $\begin{array}{c}\text { Control group } \\
(\mathrm{n}=50)\end{array}$ & $\begin{array}{c}\mathrm{P} \\
\text { value }\end{array}$ \\
\hline Birth weight $(\mathrm{gm})$ & $2678 \pm 34$ & $2616 \pm 42$ & $>0.05$ \\
Gestational age $(\mathrm{wk})$ & $37.7 \pm 0.5$ & $37.4 \pm 0.2$ & $>0.05$ \\
Apgar score at 10 min & $4.2 \pm 0.3$ & $4.1 \pm 0.4$ & $>0.05$ \\
Male/female $(\mathrm{n}, \%)$ & $27 / 23(54 \% / 46 \%)$ & $24 / 26(48 \% / 52 \%)$ & $>0.05$ \\
Mode of deliveryCesarean/NVD $(\mathrm{n}, \%)$ & $41 / 9(82 \% / 18 \%)$ & $39 / 11(78 \% / 22 \%)$ & $>0.05$ \\
\hline
\end{tabular}

Table-II

Outcome measured in the neonates of both the study groups.

\begin{tabular}{lccccc}
\hline Outcome & \multicolumn{2}{c}{$\begin{array}{c}\text { Case group } \\
(\mathrm{n}=50)\end{array}$} & \multicolumn{2}{c}{$\begin{array}{c}\text { Control group } \\
(\mathrm{n}=50)\end{array}$} & $\begin{array}{c}\mathrm{P} \\
\text { value }\end{array}$ \\
\hline Seizure & 4 & $(8 \%)$ & 6 & $(12 \%)$ & $>0.05$ \\
Neurological abnormality at discharge & 5 & $(10 \%)$ & 7 & $(14 \%)$ & $>0.05$ \\
Mortality & 6 & $(12 \%)$ & 7 & $(14 \%)$ & $>0.05$ \\
Major neurological disability at 1 year of age & 7 & $(14 \%)$ & 9 & $(18 \%)$ & $>0.05$ \\
\hline
\end{tabular}

Table-III

Prediction of clinical outcome in perinatal asphyxia in term neonates.

\begin{tabular}{lccc}
\hline Outcome & Odds & $95 \%$ Confidence & $P$ \\
& ratio & Interval & value \\
\hline Seizure & 0.66 & $0.17-2.50$ & 0.54 \\
Neurological abnormality at discharge & 0.71 & $0.21-2.40$ & 0.58 \\
Mortality & 0.85 & $0.26-2.73$ & 0.79 \\
Major neurological disability at 1 year of age & 0.77 & $0.26-2.25$ & 0.64 \\
\hline
\end{tabular}




\section{Discussion}

Phenobarbital is believed to exert a neuroprotective effect partially by reducing brain metabolism and oxygen intake. ${ }^{12}$ The vasoconstrictive effect of phenobarbital reduces cerebral edema ${ }^{15}$ and reperfusion injury after the acute phase of asphyxia. ${ }^{16}$ However, few clinical trials of barbiturates in asphyxiated newborns in developed countries have shown marginal or no beneficial results and reported remarkable hemodynamic adverse effects. ${ }^{13}$ In a study, early phenobarbital use was associated with a three-fold increase in the incidence of later seizures in term newborns with perinatal asphyxia. ${ }^{11}$ In this study, prophylactic phenobarbitone was given as 20 $\mathrm{mg} / \mathrm{kg}$ intravenously slowly over 20 minutes in the case group before the occurrence of seizures while standard treatment of perinatal asphyxia was given to the control group. Both the study groups were comparable in birth weight, gestational age, sex ratio, mode of delivery and Apgar score at 10 minutes ( $p$ value $>0.05$ ). In our study, clinical outcome such as seizure was not significantly prevented by prophylactic phenobarbitone therapy in the case group as compared to the control group ( $8 \%$ vs. $12 \%$, OR 0.66 , $95 \% \mathrm{Cl} 0.17-2.50, \mathrm{p}>0.05)$, which is similar to the previous study. ${ }^{13,14}$ However, these results were inconsistent with the results of a previous study where high dose phenobarbital in term newborns with severe perinatal asphyxia was associated with a $27 \%$ reduction in the incidence of seizures. ${ }^{5}$

Other clinical outcome, neurological abnormalities, such as hypotonia, poor reflexes at discharge (10\% vs. $14 \%$, OR $0.71,95 \% \mathrm{Cl} 0.21-2.40, \mathrm{p}>0.05)$ and number of death $(12 \%$ vs. $14 \%$, OR $0.85,95 \% \mathrm{Cl}$ $0.26-2.73, \mathrm{P}>0.05$ ) were comparable in both the case and the control groups, there was no significant difference in this regard between the two groups in this study. In the previous studies, similar results were found. ${ }^{15,16}$

The study subjects were followed up periodically at three months interval up to one year of age to evaluate major neurological disability e.g. cerebral palsy, seizure disorder (epilepsy), there was no significant difference between the case and the control groups (14\% vs. $18 \%$, OR $0.77,95 \%$ Cl 0.26-2.25, P > 0.05). Similar results were found in the previous study. ${ }^{11}$

\section{Conclusion}

Prophylactic phenobarbitone therapy did not significantly prevent seizures in perinatal asphyxia; similarly it did not significantly reduce mortality, neurological abnormalities at discharge and major neurological disabilities such as cerebral palsy and epilepsy. Further studies are necessary to evaluate the usefulness of prophylactic phenobarbital therapy in perinatal asphyxia.

\section{References}

1. Hakan N, Aydin M, Yilmaz O, Zenciroglu A, Okumus $\mathrm{N}$. Is phenobarbital a neuroprotective agent in newborn infants with perinatal asphyxia? PediatrInt 2014;56(1):128.

2. Massaro AN, Govindan RB, Vezina G, Chang T, Andescavage NN, Wang $\mathrm{Y}$, et al. Impaired cerebral autoregulation and brain injury in newborns with hypoxic-ischemic encephalopathy treated with hypothermia. J Neurophysiol 2015: in.00353.2015. [PubMed]

3. Douglas-Escobar M, Weiss MD. Hypoxicischemic encephalopathy: a review for the clinician. JAMA Pediatr 2015;169(4):397-403.

4. Kitai Y, Ohmura K, Hirai S, Arai H. Long-term outcome of childhood hypoxic-ischemic encephalopathy. No To Hattatsu 2015;47(1):438.

5. Avasiloaiei A, Dimitriu C, Moscalu M, Paduraru L, Stamatin M. High-dose phenobarbital or erythropoietin for the treatment of perinatal asphyxia in term newborns. PediatrInt 2013;55(5):589-93.

6. Douglas-Escobar M, Weiss MD. Biomarkers of hypoxic-ischemic encephalopathy in newborns. Front Neurol 2012;3:144.

7. Buonocore G, Perrone S, Turrisi G, Kramer BW, Balduini W. New pharmacological approaches in infants with hypoxic-ischemic encephalopathy. Curr Pharm Des 2012;18(21):3086-100.

8. Sarkar S, Barks JD, Bapuraj JR. Does phenobarbital improve the effectiveness of therapeutic hypothermia in infants with hypoxicischemic encephalopathy? J Perinatol. 2012;32(1):15-20.

9. Gathwala G, Marwah A, Gahlaut V, Marwah P. Effect of high-dose phenobarbital on oxidative stress in perinatal asphyxia: an open label 
randomized controlled trial. Indian Pediatr 2011;48(8):613-7.

10. Herrera-Marschitz M, Morales P, Leyton L, Bustamante D, Klawitter V, Espina-Marchant P, et al. Perinatal asphyxia: current status and approaches towards neuroprotective strategies, with focus on sentinel proteins. Neurotox Res 2011;19(4):603-27.

11. Lai M-C, Yang S-N. Perinatal Hypoxic-Ischemic Encephalopathy. J Biomed Biotechnol 2011; 609813. [PubMed]

12. Allen KA, Brandon DH. Hypoxic Ischemic Encephalopathy: Pathophysiology and Experimental Treatments. Newborn Infant Nurs Rev 2011;11(3):125-33.

13. Filippi L, la Marca G, Cavallaro G. Phenobarbital for neonatal seizures in hypoxic ischemic encephalopathy: a pharmacokinetic study during whole body hypothermia. Epilepsia. 2011; 52(4):794-801.
14. Glass HC, Nash KB, Bonifacio SL. Seizures and magnetic resonance imaging-detected brain injury in newborns cooled for hypoxic-ischemic encephalopathy. J Pediatr. 2011;159(5):731-5.

15. Edwards AD, Brocklehurst P, Gunn AJ. Neurological outcomes at 18 months of age after moderate hypothermia for perinatal hypoxic ischaemic encephalopathy: synthesis and metaanalysis of trial data. BMJ. 2010;340-63.

16. MeynJr DF, Ness J, Ambalavanan N, Carlo WA. Prophylactic phenobarbital and whole-body cooling for neonatal hypoxic-ischemic encephalopathy. J Pediatr 2010; 157(2): 334-6.

17. Kumar S, Paterson-Brown S. Obstetric aspects of hypoxic ischemic encephalopathy. Early Hum Dev 2010;86(6):339-44.

18. Fatemi A, Wilson MA, Johnston MV. Hypoxicischemic encephalopathy in the term infant. Clin Perinatol 2009;36(4):835-58. 